\title{
Screening of colorectal tumours using an improved faecal occult blood test. Quantitative aspects
}

\author{
I HÄKKINEN, R PAASIVUO, AND P PARTANEN \\ From the Department of Pathology, University of.Turku and Labsystems Research Laboratories, Helsinki, \\ Finland
}

SUMmARY A recently developed double test for detecting faecal occult blood (a sensitive guaiac test combined with a quantitative immunological human haemoglobin test), was adapted to population screening. The study involved an unselected population of 10343, aged 49-74 years. There was 66.5\% participation. 174 colonoscopies were done, yielding seven adenocarcinomas, 44 adenomas and four hyperplastic polyps. By eliminating benign anal tract bleeding, the number of endoscopies decreased from 340 to 174 . Most tumours showed an absorbance over $0 \cdot 80$, and it is suggested that by setting the lower limit of positivity at the 0.80 absorbance level, the number of clinical examinations could fall to about $1 \%$, without substantially missing tumours.

The weakness in sensitivity-specificity of various guaiac tests in the detection of faecal occult blood is well recognised. ${ }^{2}$ If adapted to a more sensitive level, false positives prevail, if made insensitive to avoid that, a substantial number of bleedings are missed. Another weakness is the common acceptance of visual interpretations of qualitative colour tests.

The problem can be approached in another way. By adjusting the guaiac test to its most sensitive level, all significant bleedings will be included, as well as the false positive cases. ${ }^{3}$ To differentiate these, a second test is used, a specific immunochemical determination of human haemoglobin. ${ }^{4}$ Particularly important is that the test is a quantitative colorimetric determination and is easy to reproduce.

In a pilot experiment on a small population (unpublished data) it appeared that by utilising the whole scale of sensitivity of the quantitative immunotest, a group of bleeders was detected including mainly benign conditions and physiological diffusion leakage. This being especially true in the lower $0.20-$ 0.39 absorbance level of the immunotest. The load of clinical examinations grew too high. Similar experience was derived from an earlier population studys using the same double phase faecal occult blood test.

The above observations made it necessary to adopt

Address for correspondence: Dr I Häkkinen, Dept of Pathology, University of Turku, 20520 Turku, Finland.

Received for publication 12 April 1988. a more radical approach by discharging the smaller bleedings. In this case the question is not of false positive because FECA-EIA only measures human haemoglobin but rather of the origin of the bleeding, a tumour versus other cause. As the FECA-EIA determination is colorimetric it allows setting of the lower limit of positiveness to a desired and easily reproducible level. The aim was to gain in tumour specificity and to minimise the number of clinical examinations.

\section{Methods}

SUBJECTS

The study was performed among an unselected population in seven communities in southwestern Finland. The study had been approved by consecutive committees of the local Health Service. All male and female inhabitants within the age group 49-74 years, 10343 altogether, were sent an informative letter of invitation which thoroughly described the method as well as the purpose of the study and emphasised that participation was voluntary. Sampling equipment and dietary requirements for the Fecatwin S method ${ }^{3}$ was enclosed with the letter.

\section{STUDY SCHEDULE}

Faecal samples taken at patient's homes in three standard test cases were collected at local Health Stations, and were sent for analysis. All guaiac 
Table 1 Data on the screening procedure (unselected population, age group 49-74)

\begin{tabular}{lc}
\hline Participated & 6878 \\
FECA-TwinS positive & 3719 \\
FECA-EIA positive & 340 (over $0 \cdot 40$ absorbance) \\
Primarily endoscopied & 118 \\
$\begin{array}{l}\text { Endoscopied after treatment of benign anal tract } \\
\text { bleeding }\end{array}$ & 56 \\
Total endoscopied & $174(2 \cdot 5 \%)$ \\
No bleeding after treatment of benign anal tract & 149 \\
$\quad$ disorder & 17 \\
No further participation & \\
\hline
\end{tabular}

positive samples were reanalysed using the quantitative FECA-EIA ${ }^{\circledR}$ test*. The results were expressed as absorbance figures of the colorimetric determination. Subjects with EIA positives of over 0.40 absorbance were invited for clinical examination. In the group of low positives (absorbance between $0 \cdot 20-0 \cdot 39$ ), a new faecal sample was taken after six months, for the purpose of following this group.

The first stage of the clinical examination included a personal interview which was intended to reveal any information on benign bleedings from the anal tract, piles, or fissurae. These bleedings were treated by conservative means, and afterwards a new faecal sample was analysed. In cases where the EIA test still showed an absorbance value over $0 \cdot 40$, a colonoscopy was carried out. In cases where no bleeding from the anal tract was evident, a colonoscopy was carried out primarily.

\section{Results}

The acceptability (Table 1) was a satisfactory $66.5 \%$, gained without any reminders.

A Fecatwin S positive test result was found in 3719 of those who participated. When a FECA-EIA immunotest was done on all guaiac positive samples, altogether 526 EIA-positive bleedings were found (7.7\% of those who participated). Quantitatively,

*Fecatwin S - FECA-EIA, Trade Marks of Labsystems Co, Pulttitie 8, Box 8, 00881 Helsinki, Finland.
186 of these were between $0 \cdot 20-0 \cdot 39$ colorimetric absorbance level, whereas $340(4 \cdot 9 \%)$ exceeded $0 \cdot 40$ absorbance, and were considered as positives in this study. Among these 340 persons, a very careful clinical interview revealed anal tract bleeding from piles or fissurae in 205 cases. After temporary treatment of these bleedings, with aid of suppositories and ointments, in 149 cases a faecal retest was negative. This group was not examined further.

When the remaining 56 persons with continuous bleeding were examined by endoscopy, in 12 cases a tumour was found behind piles as a secondary source of bleeding. When the 118 persons with an apparently healthy anal tract were endoscopied, a tumour was detected in 43 cases altogether (Table 2).

In the group of low absorbance positives, 186 persons; a second faecal sample was positive after 6 months at over the 0.40 absorbance level in only 25 cases. Of these, 13 had piles as the only source of bleeding. When the remaining 12 persons were examined by endoscopy, only one small adenoma was found in this follow up group.

With all these eliminating measures - that is, after a primary screening with a sensitive guaiac test, a raised lower limit in the evaluation of the final immunotest, and the clearing up of anal tract bleedings, we had to carry out a colonoscopy in 174 cases ( $2 \cdot 5 \%$ of the participants). In 46 cases where colonoscopy was not completed, a double contrasted barium enema was used.

Table 2 illustrates the histological diagnosis, and the size and bleeding tendency of the tumours. Seven adenocarcinomas, 44 adenomas of various histological structures, and four hyperplastic polyps were found, 55 tumours altogether. These figures represent numbers of people. In six instances where two to three adenomas were present simultaneously, the biggest and that most evidently bleeding was counted. In endoscopical evaluation of the bleeding tendency of the tumour, 48 tumours were evidently bleeding whereas in seven cases bleeding was not apparent.

Table 2 Clinical diagnosis, tumour size, bleeding or not bleeding

\begin{tabular}{|c|c|c|c|c|c|c|}
\hline \multirow[b]{2}{*}{ Diagnosis } & \multirow[b]{2}{*}{$n$} & \multirow[b]{2}{*}{ Bleeding } & \multirow[b]{2}{*}{ No bleeding } & \multicolumn{3}{|c|}{ Tumour size } \\
\hline & & & & $0.5-1 \mathrm{~cm}$ & $I-2 \mathrm{~cm}$ & 2 or more $\mathrm{cm}$ \\
\hline \multicolumn{7}{|l|}{ Adenocarcinoma } \\
\hline moderately differentiated & 6 & 6 & 0 & & & 6 \\
\hline poorly differentiated & 1 & 1 & 0 & & & 1 \\
\hline Villous adenoma & 2 & 2 & $\mathbf{0}$ & & & 2 \\
\hline Tubulovillous adenoma & 13 & 13 & 0 & 2 & 3 & 8 \\
\hline Tubular adenoma & 29 & 24 & 5 & 15 & 9 & 5 \\
\hline Hyperplastic polyp & 4 & 2 & 2 & 3 & 1 & \\
\hline Tumours total & 55 & 48 & 7 & 20 & 13 & 22 \\
\hline Ulcerative colitis & 10 & & & & & \\
\hline
\end{tabular}


Table 3 Bleeding quantity (absorbance) versus tumour distance from anus

\begin{tabular}{|c|c|c|c|c|c|c|c|}
\hline \multirow{2}{*}{\multicolumn{2}{|c|}{$\begin{array}{l}\text { Distance } \\
\text { from anus } n\end{array}$}} & \multicolumn{6}{|c|}{ Absorbance } \\
\hline & & 0.40 & 0.50 & 0.60 & $0 \cdot 70$ & $0 \cdot 80$ & 1.0 or more \\
\hline $5-20 \mathrm{~cm}$ & 17 & 2 & 1 & & & 3 & 11 \\
\hline$-35 \mathrm{~cm}$ & 25 & 1 & 3 & & 1 & 4 & 16 \\
\hline$-60 \mathrm{~cm}$ & 10 & 2 & & 2 & & 2 & 4 \\
\hline$-90 \mathrm{~cm}$ & 3 & & & & & 1 & 2 \\
\hline Total & 55 & 5 & 4 & 2 & 1 & 10 & 33 \\
\hline
\end{tabular}

Table 3 shows the absorbance figures in tumour cases. The Table also gives the distance of the tumour from the anus. Evidently, most tumour cases are above the 0.80 absorbance level, among them all tumours situated more than $60 \mathrm{~cm}$ from the anus. Only 12 tumours gave a lower absorbance between 0.40 and 0.70 . In the total group of over 0.40 absorbance bleeders, 340 persons, $178(2.6 \%)$ were in the $0 \cdot 40-0 \cdot 80$ level.

\section{Discussion}

A Danish faecal occult blood screening has been carried out recently on the island of Funen." This study also covered an unselected population, and a similar age group to ours. The acceptability in these differed only slightly, $66.5 \%$ in our study and $69 \%$ in Denmark. It should be noted that in our study no reminders were used. In assessing the likely acceptability rates for similar screenings in the future we have to bear in mind that this was the first screening of its kind in this country. The population had no knowledge of the procedure nor of its usefulness.

The new double test Fecatwin S - FECA-EIA was now used for the first time in our country in an extensive screening for faecal occult blood. Fecatwin $S$ yielded $54.1 \%$ of positives in the population. This despite asking the participants to follow dietary restrictions. The figure is higher than expected. Whether the sensitive guaiac test is needed at all is a question of economics. Immunotests are more costly, and excluding $46 \%$ of the population by using the inexpensive guaiac test is cost effective. Reanalysis of these 3719 guaiac positive samples by means of the immunochemical human haemoglobin test (FECAEIA) yielded $7.7 \%$ of positives of over 0.20 absorbance. The lower limit of positivity for introduction of any further clinical examinations, however, was primarily set to the 0.40 absorbance level. In this way only $4.9 \%$ of the participants needed clinical examinations. In our earlier unpublished study the clinical examinations of the group of low positives $(0 \cdot 20-0 \cdot 39$ absorbance level) revealed no tumours in total 61 instances. This strongly justifies changing the lower limit of positivity. To clarify the fate of the group of low-positives in this study, 186 persons, a secondary faecal sample was taken after half a year's delay. This was intended only to reveal whether any of the subjects showed progression in their bleeding tendency. This was the case in only 25 instances. We are fully aware that the real fate of this group could be elucidated only by clinically examining them as was done in earlier studies ${ }^{5}$ and our unpublished study.

Further reduction of the number of colonoscopies was achieved when benign anal tract bleedings were revealed by means of a very careful clinical interview. Eliminating the apparent first source of bleeding by treatment cleared up the source of bleeding in 149 cases. In 56 cases further bleeding was observed, and the possibility of an upper source was apparent. Thus the total of 174 cases $(2.5 \%$ of the participants) remained for colonoscopy.

Typical of these anal tract bleedings was a lower absorbance level, below $0 \cdot 80$ in over half of the cases. On the other hand, in the group which showed continuous positivity after treatment of benign anal tract bleedings, over half of the cases belonged to the over 0.80 absorbance group. All the 12 tumours detected behind the piles showed bleeding of over 0.80 absorbance. A majority of tumour cases showed an absorbance over $0 \cdot 80$ (Table 3 ). If the limit of positivity were set at the $0 \cdot 80$ absorbance level, the number of positives would be reduced from 340 by 178 , and the number of endoscopies would decline to about $1 \%$, without essentially missing tumour cases. A larger scale study is needed, however, to confirm the above suggestion.

Our results indicate that slightly bleeding tumours are rare. When they bleed, they give a sufficient amount of blood to get out the destructive milieu in the gut, and for a specific $\mathrm{Hb}$-test to detect it. In cases where the tumour is not bleeding this principle of screening does not function at all. The total number of findings in our study indicates, however, that a substantial proportion of colorectal tumours probably bleed. Certainty can be assured only by carrying out colonoscopies on the whole population under investigation. An intermittent bleeding can cause a false negative result in the group of originally negatives as well. Ultimately the problem is how often to rescreen the actual population. This is, however, outside of the scope of the present study.

As this study was carried out among an unselected population, the figures for colorectal cancer are comparable with the data of the Finnish Cancer Registry.? Our number of cancer cases slightly exceeds the incidence figure there. As compared with the initial results of the Danish screening with Hemoccult-II, ${ }^{8} 37$ cancers and 86 adenomas together, in a population of 20672 , we can state that 
the number of our cancer cases is lower but the figure for adenomas higher than their result. It is to be pointed out, however, that the incidence of colorectal cancer in Denmark is about twice that in Finland. ${ }^{9}$ If all tumours are considered, the test used in our study may be regarded as being capable of detecting an about two-fold higher yield. Previously, the Haemoccult-II test has already been criticised for its insensitivity. ${ }^{2}$ FECA-EIA on the other hand gives us a chance to view the whole spectrum of sensitivity and clearly shows where the bleedings are really situated in the scale.

This work was supported by a project grant from the Finnish Social Insurance Institution.

\section{References}

1 Simon JB. Occult blood screening for colorectal carcinoma: A critical review. Gastroenterology 1985; 88: 820-37.

2 Williams CB, Macrae FA. The St. Mark's neoplastic polyp follow-up study. Front Gastrointest Res 1986; 10: 226-42.
3 Adlercreutz H, Partanen P, Virkola P, Liewendahl K, Turunen MJ. Five guaiac-based tests for occult blood in faeces compared in vitro and in vivo. Scand J Clin Lab Invest 1984; 44: 519-28.

4 Turunen MJ, Liewendahl K, Partanen P, Adlercreutz H. Immunological detection of faecal occult blood in colorectal cancer. Br J Cancer 1984; 49: 141-8.

5 Armitage N, Hardcastle JD, Amar SS, Balfour TW, Haynes J, James PD. A comparison of an immunological faecal occult blood test Fecatwin sensitive/FECA EIA with Haemoccult in population screening for colorectal cancer. Br J Cancer 1985; 51: 799-804.

6 Klaaborg K, Madsen MS, Søndergaard O, Kronborg O. Participation in mass screening for colorectal cancer with fecal occult blood test. Scand J Gastroenterol 1986; 21: $1180-4$.

7 Finnish Cancer Registry XXVII/1982. Cancer incidence in Finland 1982. Helsinki: Finnish Cancer Registry, 1986.

8 Kronborg O, Fenger C. Initial mass screening for colorectal cancer. A randomised study at Funen in Denmark. Scand J Gastroenterol 1987; 22: [suppl 135] 24.

9 Danish Cancer Registry. Cancer incidence in Denmark 1981 and 1982. København: Danish Cancer Registry, 1987. 